\title{
Kıvırcık koyunlarında flushinge ek olarak farklı dozlarda GKSH uygulamalarının döl verimine etkisi
}

\section{Effect on fertility of PMSG applications in different doses in addition to flushing in Kivircik ewes}

\section{Şeniz ÖZiş ALTINÇEKIÇ, Mehmet KOYUNCU, Serdar DURU}

Uludağ Üniversitesi, Ziraat Fakültesi, Zootekni Bölümü, 16059, Bursa

Sorumlu yazar (Corresponding author): Ş. Öziş Altinçekiç, e-posta (e-mail): senizozis@gmail.com

\section{MAKALE BILGISII}

Alınış tarihi 1 Kasım 2017

Düzeltilme tarihi 26 Subat 2018

Kabul tarihi 26 Şubat 2018

\section{Anahtar Kelimeler:}

Koyun

Flushing

Vaginal sünger

GKSH

Döl verimi özellikleri

\section{ÖZ}

Bu çalışmada, Kıvırcık koyunlarında flushing ve buna ek olarak farklı dozlarda gebe kısrak serumu hormonu (GKSH) uygulamasının üreme performansı üzerine etkisi incelenmiștir Araştırma materyalini daha önce bir kez doğum yapmış 100 baş Kıvırcık koyun oluşturmuştur. Araştırma materyali her birinde eşit sayıda $(\mathrm{n}=25)$ koyun bulunan dört gruba ayrılııștır Gruplardaki tüm hayvanlara flushing uygulanmıș, bir grubun dışındaki diğer 3 gruba ek olarak $20 \mathrm{mg}$ flourogestone acetate (FGA) içeren vajinal sünger uygulanmış ve sonrasında 300,400 ve $500 \mathrm{IU}$ GKSH enjekte edilmiștir. Gruplarda kızgınlıklar sırasıyla $34.86 \pm 1.73,31.91 \pm 1.63$, $36.67 \pm 1.69$ ve $45.76 \pm 1.70$ saatlerde görülmüş ve gözlenen farklılıklar önemli bulunmuştur $(\mathrm{P}<0.001)$. Gebelik oranı tüm gruplarda $\% 100$ bulunurken; kuzulama oranı, flushing ve flushing+GKSH 500 IU gruplarında diğer gruplara göre daha yüksektir. Çoğuz doğum oranı, koyun başına düşen kuzu sayısı ve yaşama gücü bakımından gruplar arasında bir fark görülmemiștir. Kuzuların doğum ağırlığı, sütten kesim ağırlığ 1 ve günlük canlı ağırlık artıșı bakımından gruplar arasında istatistiksel açıdan bir farkın olmadığı belirlenmiştir. Sonuç olarak, araştırmanın yürütüldüğ̈ Kıvırcık rrkı sürüsünde çiftleşme mevsimi dışındak dönemde flushing uygulamasına ek olarak progesteron içeren vajinal sünger+GKSH uygulamasının üreme performansı açısından belirgin bir katkısı olmadığı saptanmıştır. Bu noktada yetiștiricinin tercihine bağlı olarak doğru ve zamanlaması uygun bir flushing uygulaması ile farklı bir program uygulamadan kızgınlıkların toplulaştırılabileceği ve kuzu veriminin arttırılabileceği sonucuna ulaşı1mıștır.

\section{ARTICLE INFO}

Received 1 November 2017

Received in revised form 26 February 2018

Accepted 26 February 2018

\section{Keywords:}

Sheep

Flushing

Vaginal sponge

PMSG

Reproduction characteristics

\section{ABSTRACT}

In this study, flushing and different doses of pregnant mare serum gonadotrophin (PMSG) application in addition to this in Kivircik Sheep was reviewed on reproductive performance. Research material consisted of 100 head Kivircik sheep that have given birth one time before. The herd was divided into four groups which have equal sheep $(n=25)$. Flushing was applied to every group, 3 groups other than one group were additionally applied intravaginal $20 \mathrm{mg}$ flourogestone acetate (FGA) and then 300, 400 and 500 IU pregnant mare serum gonadotrophin (PMSG). Estrouses in the groups were observed at $34.86 \pm 1.73,31.91 \pm 1.63$, $36.67 \pm 1.69$ and $45.76 \pm 1.70$ hours and the observed differences were found significant $(\mathrm{P}<0.001)$. While the rate of pregnancy were found $100 \%$ in every group; fertility, flushing $(100 \%)$ and flushing+PMSG $500 \mathrm{IU}(100 \%)$ were found higher than the other groups. No difference was observed among the groups in terms of multiple birthrate, number of lambs per sheep and vitality. It was determined that there was no statistical difference among the groups in terms of birth weight, weaning weight and increase in daily live weight. As a result, it was identified that progesterone+PMSG application in addition to flushing application during anestrus season in Kivircik herd which the research is conducted on, had no significant contribution in terms of reproductive performance. At this point, it was concluded that with a right and seasonable flushing application based on the breeder's preference, the estrous could be synchronization and that the lamb efficiency could be increased. 


\section{Giriş}

Koyun yetiştiriciliğinde sürdürülebilirlik, üreme noktasında verimliliğin önemli bir göstergesi olan kuzulama oranının artırılmasına ve et üretimine bağlıdır. Koyunlarda üreme etkinliği başta besleme olmak üzere birçok çevresel faktörle çok yakından ilişkilidir. Koyun yetiştiriciliğinde koç katımından 2-3 hafta önce ve koç katımı esnasında koyunları yüksek enerjili yemlerle besleme şeklinde yapılan flushing uygulaması yaygın olarak kullanılmaktadır (Cirne ve ark. 2016). Rivas-Muñoz ve ark. (2010), koyunlarda yumurtlama oranına yüksek enerjili rasyonla beslemenin bir etkisi olmadığını ancak bir hafta yüksek proteinli rasyonla beslenmenin olumlu etkisinin olduğunu belirtmektedir. Diğer taraftan Crocker ve ark. (1985) ise yüksek döl verimi için protein/enerji düzeyinin kritik öneme sahip olduğunu, yüksek düzeyde protein alımının yumurtlamayı olumsuz etkilediğini bildirmişlerdir. Lassoueda ve ark. (2004), çiftleştirmeden birkaç gün önce rasyona yüksek miktarda protein katılarak döl veriminin artırılabileceğini ancak bu etkinin protein kaynaklarına göre değişiklik gösterdiğini ifade etmektedirler. Brink (1990) ise rasyondaki enerji yetersizliğinin ya da tersine aşırı enerjinin kandaki progesteron konsantrasyonunu azaltacağından erken embriyo ölümlerini artırdığını bildirmiştir.

Tüm canlılarda olduğu gibi koyunlarda da beslenme düzeyi ile üreme aktivitesi doğrudan ilişkilidir. Koyunların aşım öncesi ağırlıklarının artması, üreme mevsiminin başlangıcından sonraki kızgınlık oluşumunu, yumurtlama oranını ve doğurganlıklarını olumlu şekilde etkilemektedir (Sabra ve Hassan 2008; Hafez ve ark. 2011). Çiftleşme öncesi flushing uygulamasının birçok koyun 1rkında yumurtlama ve kuzulama oranlarını arttırdığı bildirilmektedir (Naqvi ve ark. 2011). Bir başka ifadeyle, flushing uygulaması koyunlarda yumurtlamayı teşvik etmekte, yumurtlama hızını, embriyo yaşayabilirliğini ve koyun başına doğan kuzu sayısını artırmaktadır (Abu El- Ella 2006; Scaramuzzi ve ark. 2006). Hatta döllenmeden sonraki bir ay daha flushing uygulamasina devam edilmesinin embriyonun tutunması ve sağ kalması açısından da önemli olduğu belirtilmektedir (Nogueira ve ark. 2011). Bununla birlikte bu etki, flushing süresi, rasyonun kalitesi ve miktarı, hayvanın vücut kondisyon skoru ve mevsim gibi birçok faktöre bağlı olarak değişmektedir (Gonźalez-Bulnes ve ark. 2004; Hafez ve ark. 2011). Koyunlarda döl veriminin artırılması, en başta sürü düzeyinde aşımların zamanında ve düzenli olarak gerçekleşmesiyle mümkündür. Yüksek düzeyde kızgınlık yanıtının oluşturulması ve başarılı gebeliğin sağlanması noktasında progesteron içeren vajinal süngerler pratik, uygulanması kolay ve yüksek oranda başarı elde edilmesi nedeniyle daha çok tercih edilmektedir (Kusina ve ark. 2000). Koyunlarda vajinal sünger uygulaması sonunda düşük dozda GKSH uygulaması, yumurtlamanın gerçekleşmesini ve uygulama sonrası döl verimini artırmak ve daha güvenilir kızgınlık senkronizasyonu elde etmek amacı ile de kullanılmaktadır (Üstüner ve ark. 2007). GKSH kullanımı, kızgınlık belirtilerinin daha erken başlamasına, daha belirgin ve uzun sürmesine neden olur (Yıldız ve ark. 2004). Ancak yumurtlama oranı kullanılan GKSH dozu tarafindan etkilenmektedir (Simonetti ve ark. 2002). Yeterli dozdaki GKSH kuzu verimini arttırırken, yüksek dozda kullanımı çoğuz gebeliklerin oluşmasına veya doğum sonrası kuzu ölümlerinde artışa neden olabilmektedir (Ataman ve ark. 2006). Altınel ve Haciislamoğlu (1993), Tahirova koyunlarında progesteron içeren vajinal sünger uygulamasına ek olarak 500 IU GKSH enjeksiyonu sonucunda çoğuz doğum oranını \% 84.48, koyun başına düşen kuzu sayısını iki olarak belirlemiştir. Çolak ve ark. (1996), Morkaraman ve Tuj 1rk1 koyunlara progesteron içeren vajinal süngerler çıkarıldığı gün 400 IU GKSH enjeksiyonu sonucu \% 95.83 oranında gebelik elde edildiğini, Zonturlu ve ark. (2008) ise koyunlara çiftleşme mevsimi dişındaki dönemden çiftleşme mevsimine geçişte progesteron içeren vajinal sünger uygulamasına ek olarak 300 IU $\mathrm{GKSH}$ uygulamas1 sonucu \% 84.2 kızgınlık ve $\% 52.63$ gebelik oran1 elde edildiğini ifade etmektedir.

$\mathrm{Bu}$ çalışmada Kıvırcık ırkı koyunlarda çiftleşme mevsimi dışındaki dönemde flushing uygulamasına ek olarak $20 \mathrm{mg}$ fluorogestone acetate içeren vajinal sünger uygulaması ile kombine edilen 300,400 ve 500 IU GKSH enjeksiyonlarının döl verimine etkisi ortaya konulmaya çalışılmıştır.

\section{Materyal ve Yöntem}

\subsection{Hayvan materyali}

$\mathrm{Bu}$ araştırmada, Uludağ Üniversitesi Ziraat Fakültesi Araştırma ve Uygulama Çiftliği'nde yetiştirilen daha önce bir kez doğum yapmış 100 baş 2 yaşlı Kıvırcık koyunu kullanılmıştır. Etik kurul izni alınmıştır (2015/10-02). Bu çalışma çiftleşme mevsimi dışındaki dönemde yürütülmüştür. Tüm koyunlara flushing, çiftleşme döneminden önceki ve çiftleşme döneminin başlangıcından itibaren iki hafta olmak toplam dört hafta boyunca uygulanmıştır. Hayvanların kondisyonlarının iyi olması nedeniyle flushing uygulaması için bir aylık süre yeterli görülmüştür. Ele alınan dönem boyunca koyun başına ortalama $500 \mathrm{~g}$ (2600 ME, \% 16 ham protein) hesaplanarak grup yemlemesi yapılmıştır. Koyunlar rastgele seçilerek flushing $(n=25)$, GKSH 300 IU $(n=25)$, GKSH $400 \mathrm{IU}(\mathrm{n}=25)$ ve GKSH 500 IU $(n=25)$ olmak üzere dört gruba ayrılmıştır. Hayvanların önünde sürekli olarak temiz su ve mineral gereksinimlerinin karşılanması için yalama taşı bulundurulmuştur. GKSH gruplarında kızgınlıklar, vajina içi $20 \mathrm{mg}$ flourogestone acetate (FGA) içeren süngerlerin (Chronogest, grey sponges, İntervet-Türkiye) 12 gün süreyle tutulmasıyla senkronize edilmiştir. Süngerlerin çıkarıldığı gün koyunlara üç farklı dozda GKSH (Chronogest/PMSG, İntervetTürkiye) kas içi enjekte edilmiştir. Sadece flushing grubundaki koyunlara herhangi bir hormonal uygulama yapılmamıştır. Süngerlerin çıkarılmasını izleyen beş gün boyunca 12 saat aralıklarla günde iki kez 30 dakika süreyle arama koçları ile kızgınlık belirlenmeye çalışılmıştır. Kızgın olduğu saptanan koyunlar damızlık koçlarla bir arada tutularak serbest aşım uygulanmıştır.

Doğan kuzuların doğum sonrası ilk bir saat içerisinde kolostrum almaları sağlanmıştır. İkinci haftadan itibaren anne sütüne ek olarak kuzu başına günde $50 \mathrm{~g}$ kuzu başlangıç yemi ve kaliteli kuru yonca verilmiştir. Daha sonra sütten kesilinceye kadar (120. gün) işletmede hazırlanan rasyondan günde kuzu başına 650-700 g tüketilebilecek şekilde yemleme yapılmıştır.

\subsection{Döl verim ölçütlerinin belirlenmesi}

Araştırmada kızgınlık yanıtı, süngerlerin çıkarılmasını izleyen saatten itibaren koyunların arama koçlarının atlamasına izin verdiği saat olarak tespit edilmiştir. Üreme sonuçlarına ilişkin gebelik oranı, kuzulama oranı, doğuran koyun başına düşen kuzu sayısı, koçaltı koyun başına doğan kuzu sayısı, tek doğum oran1, ikiz doğum oran1, çoklu doğum oran1, sütten kesime kadar yaşama gücü ve günlük canlı ağırlık artışı gibi tanımlayıcı değerler aşağıda belirtilen şekilde saptanmıştır (Kaymakçı 2006). 
Gebelik Oranı $(\%)=($ Gebe koyun sayısı / Koçaltı koyun say1s1) x 100

Kuzulama oranı (Fertility, \%)= (Doğuran koyun sayısı / Koçaltı koyun sayısı) x 100

Çoğuz doğum oranı $(\%)=($ Çoğuz doğuran koyun sayısı $/$ Doğuran koyun sayıs1) x 100

Doğuran koyun başına doğan kuzu sayısı (DKDK, baş)= Doğan kuzu sayıs1/ Doğuran koyun sayıs1

Koçaltı koyun başına doğan kuzu sayısı (KKDK, Fecundity, \% $=($ Doğan kuzu sayısı $/$ Koç altı koyun sayıs1 $) \mathrm{x}$ 100

Yaşama gücü $(\%)=($ Sütten kesilen kuzu sayısı / Doğan kuzu say1s1) x 100

Günlük Canlı Ağırlık Artışı $($ GCAA $)=($ Sütten kesim ağırlığı - Doğum ağırlığı) / Sütten kesime kadar geçen süre

\subsection{Istatistiksel analizler}

Uygulamaların kızgınlık süresine etkisini araştırmak için varyans analizi yapılmışıır. Farklı grupların tespitinde LSD çoklu karşılaştırma testinden yararlanılmıştır. Kullanılan istatistiksel model aşağıdaki gibidir:

$$
\begin{aligned}
& Y_{i j}=\mu+a_{i}+b X_{i j}+e_{i j} \\
& Y_{i j}=i \text {. uygulamadaki } j \text {. ananın östrus süresi } \\
& \mu=\text { Populasyonun beklenen ortalamas1 } \\
& a_{i}=i \text {. gruptaki i.uygulamanın etkisi } \\
& \text { bX } X_{i j=} \text { i. gruptaki j.ananın ağırlığ } 1 \\
& e_{i j=}=\text { Hata etkisi }
\end{aligned}
$$

Çalışmada elde edilen verilerin değerlendirilmesi Minitab $\underline{\text { (2013) }}$ paket programı kullanılarak yapılmıştır. Uygulamaların çoğuz doğum, kuzu sayısı ve yaşama gücüne etkilerinin önemli olup olmadığ Khi-kare $\left(\chi^{2}\right)$ testiyle kontrol edilmiştir.

\section{Bulgular}

Tüm gruplarda döl verimine ilişkin elde edilen sonuçlar Tablo 1'de verilmiştir. Kızgınlık yanıtı açısından gruplar arasındaki farklılıklar istatistiksel olarak önemli bulunmuştur $(\mathrm{P}<0.001)$. Sadece flushing grubunda kızgınlığın başlaması flushing uygulamasina ek olarak GKSH uygulanan gruplara göre daha uzun sürmüştür. Kuzulama oranı GKSH 500 ve flushing gruplarında diğer iki gruba göre istatistiki olarak önemli olmamakla birlikte daha yüksektir. Benzer şekilde GKSH 400 grubunda doğuran koyun başına kuzu sayısı ve çoğuz doğum oranı diğer gruplardan daha yüksek bulunmasına karşın aralarındaki fark önemsizdir. Yavru doğum ağırlı̆̆ en yüksek grup GKSH 300 iken, sütten kesim ağırlığı en yüksek olan grup GKSH 500 olmuştur. Yavru doğum ağırlığı bakımından en alt sirada bulunan flushing grubu GCAA bakımından ilk sırada yer almıştır.

\section{Tartışma ve Sonuç}

Koyunlarda çiftleşme mevsimi başlangıcı ve uzunluğu üzerine 1 rk, çevre sıcaklığ mera şartları gibi pek çok çevresel faktör etkilidir. Yürütülen bu çalışmada, gruplara özgü kızgınlık yanıtı bakımından flushing+GKSH grupları arasında benzerlik bulunmasına karşın sadece flushing uygulanan grupta bu yanıtın oluşması için geçen süre daha uzun olmuştur. Çünkü eksojen progesteron uygulamasının sonunda yapılan GKSH enjeksiyonu, FSH ve LH benzeri bir etki göstererek kızgınlığ GKSH hormonu koyunlarda folliküler gelişimin desteklenmesinde çiftleşme mevsimi içinde veya dışında yaygın olarak kullanılmaktadır (Abecia ve ark. 2012). Ancak bu çalışmada flushing grubu için belirlenen kızgınlık görülme süresi, Köse ve ark. (2016)'nın flushing grubu için tespit etmiş oldukları kızgınlık başlama süresi olan 290 saate göre çok düşüktür. Bu farklılıkta ırkın, mevsimin ve bakım koşullarının etkili olduğu düşünülmektedir.

Köse ve ark. (2016), GKSH 300 ve GKSH 500 ve flushing gruplarında gebelik oranını sirasiyla $\% 84, \% 83$ ve $\% 80$; Shahneh ve ark. (2008), GKSH 600, flushing+ GKSH 600 ve flushing gruplarında gebelik oranını sırasıyla \% 91.3, \% 91.3 ve $\% 100$ olarak tespit etmişlerdir. Nosrati ve ark. (2011) gebelik oranı bakımından GKSH'nun 300 IU, 400 IU, 500 IU ve 600 IU dozları arasında fark olmadığını bildirmiştir. Bu araştırmada da benzer şekilde gruplar arasında gebelik oranları bakımından farklılık görülmemiştir. Kuzulama oranları incelendiğinde GKSH 500 ve flushing grupları, birer koyunun ölü doğum yapmış olması nedeniyle de GKSH 300 ve GKSH 400 grupları benzerlik göstermiştir. Aynı zamanda bu sonuçlar gebelik ve çoğuz doğum oranını artırma bakımından flushing uygulamasına ek olarak GKSH uygulanmasının ekstra bir katk1 sağlamadığını göstermektedir. Muthuramalingam ve ark. (2014) flushing uygulaması sonucu tekiz ve çoğuz doğum oranlarını sırasıyla \% 6.6 ve \% 86.6 olarak tespit etmişlerdir. Köse ve ark. (2016), GKSH 300 ve GKSH 500 ve flushing gruplarında çoğuz

\begin{tabular}{|c|c|c|c|c|c|c|}
\hline \multirow{2}{*}{ Parametreler } & \multicolumn{4}{|c|}{ Uygulamalar } & \multirow{2}{*}{ P-Değeri } & \multirow{2}{*}{$\chi^{2}$} \\
\hline & GKSH 300 & GKSH 400 & GKSH 500 & Flushing & & \\
\hline Kızgınlık yanıtı (saat) & $34.86 \pm 1.73^{\mathrm{b}}$ & $31.91 \pm 1.63^{\mathrm{b}}$ & $36.67 \pm 1.69^{b}$ & $45.76 \pm 1.70^{\mathrm{a}}$ & 0.000 & \\
\hline Gebelik oranı $(\%)$ & $100(25 / 25)$ & $100(25 / 25)$ & $100(25 / 25)$ & $100(25 / 25)$ & & \\
\hline Kuzulama oranı (\%) & $96(24 / 25)$ & $96(24 / 25)$ & $100(25 / 25)$ & $100(25 / 25)$ & & \\
\hline DKDK (baş) & $1.25(30 / 24)$ & $1.42(34 / 24)$ & $1.32(33 / 25)$ & $1.28(32 / 25)$ & 0.965 & 0.27 \\
\hline Çoğuz doğum oranı (\%) & $25(6 / 24)$ & $33(8 / 24)$ & $32(8 / 25)$ & $28(7 / 25)$ & 0.918 & 0.50 \\
\hline KKDK $(\%)$ & $125(30 / 24)$ & $142(34 / 24)$ & $132(33 / 25)$ & $128(32 / 25)$ & & \\
\hline Yaşama gücü (\%) & $90(27 / 30)$ & $100(34 / 34)$ & $91(30 / 33)$ & $97(31 / 32)$ & 0.220 & 4.36 \\
\hline Doğum ağırlığı (kg) & $4.18 \pm 0.55$ & $4.05 \pm 0.55$ & $4.11 \pm 0.86$ & $3.99 \pm 0.71$ & 0.463 & \\
\hline Sütten kesim ağırlığ $1(\mathrm{~kg})$ & $33.94 \pm 5.37$ & $33.00 \pm 4.62$ & $35.50 \pm 4.63$ & $34.85 \pm 4.78$ & 0.556 & \\
\hline $\operatorname{GCAA}(\mathrm{g})$ & $250 \pm 0.04$ & $270 \pm 0.05$ & $330 \pm 0.06$ & $340 \pm 0.06$ & 0.163 & \\
\hline
\end{tabular}
doğum oranını \% 30, \% 45 ve \% 12; Mohajer ve ark. (2012) flushing uygulanan koyunlarda çoğuz doğum oranını \% 32 olarak tespit etmişlerdir.

Tablo 1. Gruplara ait bazı üreme özellikleri.

Table 1. Some reproductive traits of the groups. 
GKSH grupları arasından GKSH 400 grubu kızgınlık yanıtının oluşma süresi, yavru verimi, çoğuz doğum oranı ve yaşama gücü oranı bakımından ön plana çıkmaktadır. GKSH 400 grubu dışındaki tüm gruplarda sütten kesim yaşına kadar 13 baş arasında kuzu ölümleri meydana gelmiştir. Bununla birlikte GKSH 500 grubundaki yaşama gücü Köse ve ark. (2016)'nın GKSH 500 grubunda elde ettiği \% 89'luk değerden yüksektir. Aynı zamanda GKSH 500 grubu GKSH grupları arasında en yüksek GCAA sağlaması ile dikkati çekmektedir. GKSH 500 grubu için tespit edilen koyun başına düşen kuzu sayısı Köse ve ark. (2016)'nın GKSH 500 grubunda elde ettiği 1.47 değerinden düşüktür. Koyunlarda GKSH'nun üreme performansı üzerine etkilerine yönelik çalışmalarda birçok faktörün sonuçlar üzerinde etkili olduğu göz önünde bulundurulursa bu sonuçların sadece uygulama dozundan kaynaklandığını söylemek zordur. Diğer yandan sadece flushing uygulanan grup kuzulama oranı, doğuran koyun başına doğan kuzu sayısı, çoğuz doğum oranı, yaşama gücü, sütten kesim ağırlığı ve GCAA bakımından GKSH 300 grubundan daha yüksek performans göstermiştir. Genel olarak koyunlarda çoklu yumurtlamayı teşvik etmek için 250-750 IU aralığında bir GKSH doz seçeneği uygulanmaktadır (Abecia ve ark. 2012).

Ravindranath ve ark. (2014), merada otlayan koyunlara GKSH uygulandığında çoğuz doğum oranının çok düşük, buna karşın flushing uygulanan gruba GKSH uygulandığında çoğuz doğumun yüksek olduğunu saptamışlardır. Ayrıca GKSH gibi eksojen bir hormona yumurtalık yanıtının düzenlenmesinde flushing uygulamasının büyük oranda etki yaptığını bildirmişlerdir. Shahneh ve ark. (2008) GKSH uygulamasının üreme performansını artırmada tek başına bir faydası olmadığını ancak flushing ile kombine edildiğinde etkisinin belirgin hale geldiğini belirtmiştir. Aynı araştırıcılar hayvana çoklu yumurtlama için gereken glukoz sağlanmadıkça tek başına uygulanan GKSH dozunun yarar sağlamadığını başka bir ifadeyle hayvanın yumurtlama oranının artırılmasının öncelikle hayvana yeterli besin maddelerinin özellikle de glukozun sağlanmasıyla mümkün olduğunu ifade etmişlerdir.

Sonuç olarak, Kıvırcık ırkı koyunlarda çiftleşme mevsimi dışındaki dönemde flushing uygulamasına ek olarak hormon uygulamanın belirgin bir farklılık yaratmadığı belirlenmiştir. Bu nedenle Kıvırcık 1rkı koyunlarda döl verimini artırmada ek maliyet getiren yapay hormonların kullanıldığı senkronizasyon uygulamalarına gerek duyulmayacağı ve flushing uygulamasının yeterli olduğu çalışmamızda ortaya konulmuştur.

\section{Kaynaklar}

Abecia JA, Forcada F, González-bulnes A (2012) Hormonal control of reproduction in small ruminants. Animal Reproduction Science 130: 173-179.

Abu El- Ella AA (2006) Response of Barki ewes to treatment with gonadotrophin hormones and energy supplementation (flushing). Egyptian Journal of Sheep, Goat and Desert Animal Sciences 1(1): 73-88.

Altınel A, Hacıislamoğlu B (1993) Koyun yetiştiriciliğinde hormon kullanılması yoluyla üremenin planlanması ve kuzu üretiminin arttırılması olanakları. İstanbul Üniversitesi Veteriner Fakültesi Dergisi 19(2): 139-144.

Ataman MB, Aköz M, Akman O (2006) Induction of synchronized oestrus in Akkaraman cross-bred ewes during breeding and anestrus seasons: the use of short-term and long-term progesterone treatments. Revue de Medecine Veterinaire 50: 257-260.
Brink DR (1990) Effects of body weight gain in early pregnancy on feed intake, body condition in late pregnancy and lamb weights. Small Ruminant Research 3: 421-424.

Cirne LGA, Sobrinho AGS, Oliveira MEF, Barbosa JC, Oliveira GJC, Bagaldo AG, Carvalho GGP, Moreno GMB (2016) Reproductive performance of Ile de France ewes under dietary supplementation before and during the breeding season. Semina: Ciencias Agrarias Londrina, 37(1): 269-278.

Crocker KP, Johns MA, Johnson TJ (1985) Reproductive performance of Merino ewes supplemented with sweet lupin seed in southern western Australia. Australian Journal of Experimental Agriculture 25: 21-26.

Çolak A, Oral H, Gürbüz A (1996) Koyunlarda aşım sezonunda FGA içeren vaginal sünger ile östrus senkronizasyonu. Doğu İlaç Fabrikası A. Ş. Veteriner Bülten. Bültendif 6: 4-6.

Gonźalez-Bulnes A, Baird DT, Campbell BK, Cocero MJ, GarcíaGarcía RM, Inskeep EK, López-Sebastián A, McNeilly AS, Santiago-Moreno J, Souza CJ, Veiga- López A (2004) Multiple factors affecting the efficiency of multiple ovulation and embryo transfer in sheep and goats. Reproduction Fertility and Development, 16(4): 421-35.

Hafez YH, Khalifa EI, El-Shafie MH, Khalek TMMA, Ahmed ME, Shehata EI (2011) Effect of energy flushing pre-mating and during mating season on production and reproduction performance of Zaraibi goats. Egyptian Journal of Sheep and Goat Sciences 6(1): 7-14.

Kaymakçı M (2006) Üreme Biyolojisi. Ege Üniversitesi Ziraat Fakültesi Yayın no: 503, İzmir.

Köse M, Kırbaş M, Bülbül B, Dursun Ş, Demirci U (2016) Akkaraman rrkı koyunlarda flushing + koç etkisi ya da farklı dozlarda gebe kısrak serum gonadotropini uygulamalaryla kuzu üretiminin arttırılabilirliğinin araştırılması. Atatürk Üniversitesi Veteriner Bilimleri Dergisi 11(1): 54-59.

Kusina NT, Tarwirei F, Hamudikuwanda H, Agumba G, Mukwena J (2000) A comparison of the effects of progesterone sponges and ear implants, PGF2 $\alpha$, and their combination on efficacy of estrus synchronization and fertility of Mashona goat does. Theriogenology 53: $1567-1580$.

Lassoueda SN, Rekik M, Mahouachi M, Ben-Hamoudac M (2004) The effect of nutrition prior to and during mating on ovulation rate, reproductive wastage, and lambing rate in three sheep breeds. Small Ruminant Research 52(2): 117-125.

Minitab (2013) Minitab ${ }^{\circledR} 17$ Statistical Software.

Mohajer M, Alimon AR, Yaakub HB, Naslaji AN, Toghdory A (2012) Effects of energy level and PMSG dose on reproductive performance of Zel ewes bred to Shal or Zel rams. Journal of Animal and Veterinary Advances 11(6): 809-813.

Muthuramalingam T, Pothiappan P, Tensingh Gnanaraj P, Devi T, Rangasamy S (2014) Effect of flushing on reproductive performance and synchronization of estrus in Tellicherry does. Indian Journal of Animal Reproduction 35(2): 34-35.

Naqvi SMK, Soren NM, Karim SA (2011) Effect of concentrate supplementation on performance, ovarian response, and some biochemical profile of Malpura ewes. Tropical Animal Health and Production 43: 905-913.

Nogueira DM, Eloy MA, Sá CO, Lopes Júnior ES, Salles HO, Sá JL, Sousa PHF (2011) Manejo Reprodutivo. In: Voltolini, T.V. Produção de ovinos e caprinos no semiárido. Petrolina: Embrapa Semiárido, p. 385-420.

Nosrati M, Tahmorespoor M, Vatandoost M, Behgar M (2011) Effects of PMSG doses on reproductive performance of Kurdi ewes artificially inseminated during breeding season. Iranian Journal of Applied Animal Science 1(2): 125-129. 
Ravindranath BM, Krishnaswamy A, Chandrashekara Murthy V (2014) Conception rate and frequency of single and multiple births in estrus synchronized Nari Suwarna ewes maintained under two different systems of feeding strategies. International Journal of Livestock Research 4(5): 42-47.

Rivas-Muñoz RE, Carrillo E, Rodriguez R, Leyva C, Mellado M, Véliz FG (2010) Effect of body condition score of does and use of bucks subjected to added artificial light on estrus response of Alpine goats. Tropical Animal Health and Production 42: 1285-1289.

Sabra HA, Hassan SG (2008) Effect of new regime of nutritional flushing on reproductive performances of Egyptian Barki ewes. Global Veterinaria 2(1): 28-31.

Scaramuzzi RJ, Campbell BK, Downing JA, Kendall NR, Khalid M, Munoz-Gutiérrez M, Somchit A (2006) A review of the effects of supplementary nutrition in the ewe on the concentrations of reproductive and metabolic hormones and the mechanisms that regulate folliculogenesis and ovulation rate. Reproduction Nutrition Development 46: 339-354.

Shahneh Z, Sadeghipanah A, Javaheri Barfourooshi H, Emami-mibody MA (2008). Effects of equine chorionic gonadotropin (eCG) administration and flushing on reproductive performance in Nadooshan goats of Iran. African Journal of Biotechnology 7(18): 3373-3379.
Simonetti L, Ramos G, Gardon JC (2002) Effect of estrus synchronization and artificial insemination on reproductive performance of merino sheep Brazilian Journal of Veterinary Research and Animal Science 9(3): 143-146.

Üstüner B, Günay U, Nur Z, Üstüner H (2007) Effects of long and short-term progestagen treatments combined with PMSG on oestrus synchronization and fertility in Awassi ewes during the breeding season. Acta Veterinaria Brno 76: 391-397.

Yıldız S, Uzun M, Kaya M, Ucar O, Genesiz O (2004) Effects of rams and luteal or follicular phase ewes on preovu-latory LH surge characteristics in ewes. Turkish Journal of Veterinary and Animal Sciences 28: 669-673.

Zonturlu AK, Aral F, Özyurtlu N, Yavuzer U (2008) Syncronization of estrous using FGA and CIDR intervaginal pessaries during the transition period in Awassi ewes. Journal of Animal and Veterinary Advances 7(9): 1093-1096. 